\title{
Prevalence of Hypertension in Children 10-18 Years of Age in Private Schools of Delhi and Their Associated Risk Factors
}

\author{
Vinita Vermaํㅗ Jaiom Dagar², Faraz Hussain Khan³, Vinod Kumar Sharma ${ }^{4}$, Reeta Baruah ${ }^{5}$
}

${ }^{1}$ Department of Paediatrics, Deen Dayal Upadhyay Hospital, New Delhi, India. ${ }^{2}$ Department of Paediatrics, Deen Dayal Upadhyay Hospital, New Delhi, India. ${ }^{3}$ Department of Paediatrics, Deen Dayal Upadhyay Hospital, New Delhi, India. ${ }^{4}$ Department of Neonatology, Deen Dayal Upadhyay Hospital, New Delhi, India. ${ }^{5}$ Department of Paediatrics, Safdarjung Hospital, New Delhi, India.

\section{ABSTRACT}

\section{BACKGROUND}

Prevalence of non-communicable diseases were considered to be rare in children. But they have increased recently in developing countries, with increase in the prevalence of paediatric overweight and obesity. Body Mass Index (BMI) is commonly used to define overweight and obesity. Positive associations have been repeatedly reported between BMI and Hypertension.

\section{METHODS}

We have conducted an observational cross sectional study of hypertension in 1250 students in the age group of 10-18 years studying in class 6 to 12 during school hours from July 2013 to June 2014. The values were recorded in multiples of $2 \mathrm{mmHg}$ and levels greater than $95^{\text {th }}$ percentile of age and gender were considered using the definition of the fourth report of NHBPEP. The association of risk factors were also evaluated.

\section{RESULTS}

Out of a total 1250 children, 239 (19.1\%) had systolic hypertension, and $216(17.3 \%)$ has diastolic hypertension. Prevalence of overweight and obesity were $11.8 \%$ and $7.5 \%$ respectively. Highly significant statistical association was found between body mass index (BMI) and both systolic and diastolic hypertension ( $p$ value 0.001).

\section{CONCLUSIONS}

Prevalence of both systolic and diastolic hypertensions were significantly high in overweight and obese children in comparison to normal weight children. Strong positive association was found between body mass index (BMI) and both systolic and diastolic hypertension. Association of other risk factors such as sex, family history, dietary habits like junk food intake and extra salt intake, were also observed.

\section{KEY WORDS}

Non-Communicable Disease, Children, Systolic Blood Pressure, Diastolic Blood Pressure, Overweight, Obese, Hypertension, Body Mass Index
Corresponding Author: Dr. Faraz Hussain Khan, F-30, 5th Floor, Abul Fazal Enclave Part - 1, Thokar no. 4, Jamia Nagar, Okhla, New Delhi - 110025. India. E-mail: farazz_89@hotmail.com

DOI: $10.14260 / j e m d s / 2020 / 132$

Financial or Other Competing Interests: None.

How to Cite This Article:

Verma V, DagarJ, Khan FH, et al. Prevalence of hypertension in children 10-18 years of age in private schools of Delhi and their associated risk factors. J. Evolution Med. Dent. Sci. 2020;9(09):593-597, DOI: 10.14260/jemds/2020/132

Submission 14-11-2019, Peer Review 03-02-2020,

Acceptance 11-02-2020,

Published 02-03-2020. 


\section{BACKGROUND}

Developing countries have shown an increase in prevalence of non-communicable diseases over the past two decades.[1] Hypertension, used to be considered rare in children, has shown an increasing trend recently, as the worldwide prevalence of paediatric overweight increases. Positive association between the two has been documented repeatedly.[2] UNICEF-WHO-World Bank Joint Child Malnutrition Estimates 2017 reports 41 million overweight children globally under the age of five. ${ }^{[3]}$ Almost half of those children were from Asia and a quarter of those from Africa. Body Mass Index (BMI) is most widely used to define overweight and obesity. Obesity plays a central role in insulin resistance syndrome, which includes hyperinsulinemia, hypertension, hyperlipidaemia, type 2 diabetes mellitus and increased risk of atherosclerotic cardiovascular diseases. ${ }^{[4]}$ Hypertension is one of the leading contributor to global disease burden and accounts for many deaths each year. Blood pressure relates in children to body weight, dietary factor, physical activity and birth weight as in adult. Hypertension is defined as systolic and/or diastolic blood pressure greater than the $95^{\text {th }}$ percentile for age and gender on at least three occasions. ${ }^{[5]}$ Blood pressure is influenced by many factors such as age, gender, height, weight, genetic factors, ethnicity, obesity, dietary intake of salt, dietary fiber, alcohol intake, physical activities (higher during and immediately after exercise and lower at rest), stress (physical and emotional), feelings (such as fear, anger and happiness) and socioeconomic status.[6] The tracking effect of Blood Pressure from childhood to adulthood has been reported in some studies, therefore the trends in blood pressure over the course of time in children may be important predictors of subsequent trends later in adult hypertension. Although blood pressure normally increases with growth and development, the children with higher level of blood pressure intend to maintain that position relative to peer group as they mature or track into higher level of blood pressure in adulthood.[7] Adolescent usually have primary or essential hypertension making up 85 to $95 \%$ of cases. Secondary hypertension is more common in preadolescent children and most of the cases are caused by renal diseases. Some other possible causes are endocrine diseases (e.g. pheochromocytoma, hyperthyroidism) and drugs (oral contra captive, Sympathomimetics, dietary supplements). Many of the risk factors that are associated with the development of hypertension are usually preventable. The transient rise in blood pressure which can be sometimes mistaken for hypertension is seen with the use of caffeine and with certain psychological factors (e.g. anxiety, stress). Studies have noted significant difference in height, weight and body mass index between low socioeconomic status (LSES) and upper socioeconomic status (USES).[8] There are only few studies examining the hypertension in children in high socioeconomic group living in urban area therefore, this was an attempt to find out the proportion of hypertension and their association in children belonging to higher socioeconomic status. This study aims to find out difference in prevalence of hypertension among overweight, obese and normal weight children of 10-18 years' age group in private schools of Delhi City, and to determine their associated risk factors, if any.

\section{METHODS}

It was a cross sectional study conducted in private schools of Delhi city during school hours from July 2013 to June 2014. All students aged 10-18 years studying in class 6 to 12 and present at the time of study in school were included in sample from each selected private school in West Delhi, India. Students suffering from chronic diseases were excluded. Name, age, sex, cast and religion were taken from school records while other information like height, weight and blood pressure were recorded on a predesigned pro forma at the time of examination. Age from school records was rounded off in completed years. Weight was measured using a digitally pre-calibrated portable weighing machine without shoes with the regular uniform and rounded off to nearest half kg. Height was measured without shoes with child standing upright using a stadiometer and rounded off to nearest one centimetre. Children who never consumed egg and meat were considered vegetarian and others as non-vegetarian. History of frequent consumption of junk/fast food was taken. Overweight was defined as BMI $\geq 85$ percentile or $\mathrm{z}$ score $\geq 1.04$ and obesity was defined as $\mathrm{BMI} \geq 95^{\text {th }}$ percentile or $\mathrm{z}$ score $\geq+1.64$. Corresponding percentile and $\mathrm{Z}$ score for BMI for age, height for age and height for age were taken from CDC 2000 chart. Blood pressure was measured in right arm in sitting position keeping the sphygmomanometer at the level of heart by auscultatory method using standard mercury manometer with appropriate size cuff for each child. The values were recorded in multiples of $2 \mathrm{mmHg}$. Systolic and/or diastolic pressure levels greater than $95^{\text {th }}$ percentile for age and gender using the definition of the fourth report of NHBPEP were considered. Expected proportion of hypertension among overweight is $17 \%$ and among normal weight is $10 \%$. To detect this difference in proportion of hypertension the sample size would be 301 in each group at 5\% error and 95\% CL (Confidence Interval) and $80 \%$ power using primer of statistic software. Expecting 25\% overweight children in affluent population and to obtain 301 overweight, we examined 1250 children.

\section{Statistical Analysis}

Data were entered on excel sheet and analysed using XLSTAT. Mean \pm standard deviation (SD) was summarized as quantitative data and $\mathrm{Z}$ test was used to analyse the difference in mean. Qualitative data was summarized in form of proportion and difference in proportion and analysed with Chi-square test. For statistical analysis, the level of significance and $\alpha$ error was $95 \%$ and $5 \%$ respectively.

\section{RESULTS}

Out of total 1250 children 239 (19.1\%) had systolic hypertension and 216 (17.3\%) had diastolic hypertension. This is statistically significant ( $\mathrm{p}$ value 0.001 ). Prevalence of overweight and obesity was seen in $11.8 \%$ and $7.5 \%$ children respectively. Out of total SBP hypertensive children 19.1\% (239), 140 were male and 99 were female. And out of total DBP hypertensive children $17.2 \%$ (215), 125 were male and 90 were female. It was statistically not significant ( $p$ value 0.345 ). 

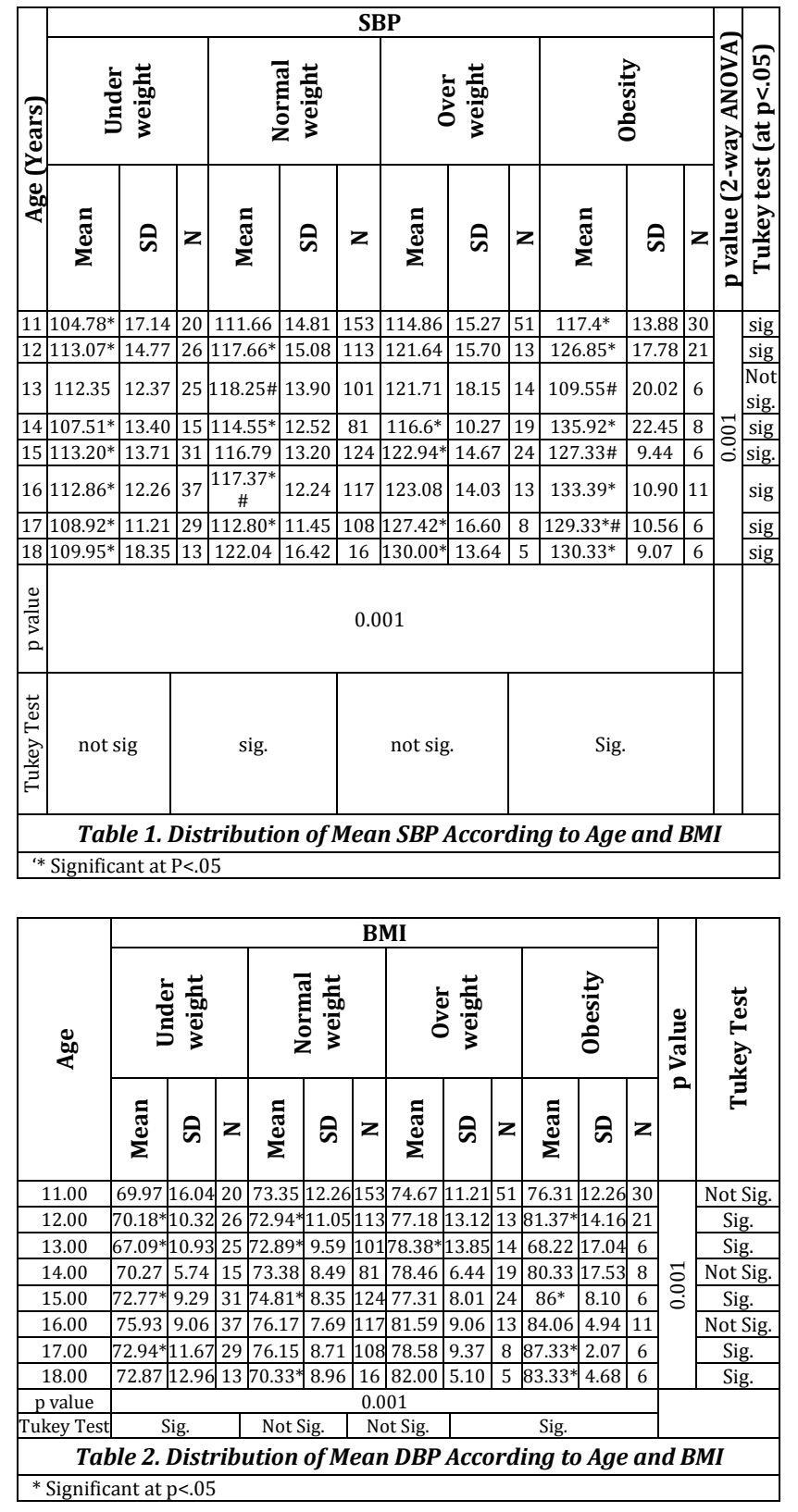

\begin{tabular}{|c|c|c|c|c|c|}
\hline \multirow{2}{*}{\multicolumn{2}{|c|}{ SBP }} & \multicolumn{2}{|c|}{ Family History } & \multirow{2}{*}{ Total } & \multirow{2}{*}{ p Value } \\
\hline & & No & Yes & & \\
\hline \multirow{2}{*}{ Normotensive } & \multirow{2}{*}{ Count } & 670 & 341 & 1011 & \multirow{6}{*}{0.499} \\
\hline & & $(66.3 \%)$ & $(33.7 \%)$ & $100.0 \%$ & \\
\hline \multirow{2}{*}{ Hypertensive } & \multirow{2}{*}{ Count } & 145 & 94 & 239 & \\
\hline & & $(60.7 \%)$ & (39.3\%) & $100.0 \%$ & \\
\hline \multirow{2}{*}{ Total } & \multirow[b]{2}{*}{ Count } & 815 & 435 & 1250 & \\
\hline & & $(65.2 \%)$ & $(34.8 \%)$ & $100.0 \%$ & \\
\hline
\end{tabular}

Table 3. Distribution of Children According to SBP and Family History

\begin{tabular}{|c|c|c|c|c|c|}
\hline \multicolumn{2}{|c|}{ Family History } & \multicolumn{2}{|c|}{ DBP } & \multirow{2}{*}{ Total } & p \\
\cline { 3 - 5 } & & Normotensive & Hypertensive & & Value \\
\hline \multirow{2}{*}{ No } & Count & 679 & 136 & 815 & \\
& & $(83.3 \%)$ & $(16.7 \%)$ & $(100.0 \%)$ \\
\hline Yes & Count & 355 & 80 & 435 & \\
\cline { 3 - 5 } & Count & $(81.6 \%)$ & $(18.4 \%)$ & $(100.0 \%)$ & \multirow{2}{*}{0.448} \\
\cline { 3 - 5 } Total & $\%$ within & $(82.7 \%)$ & $(17.3 \%)$ & 1250 & \\
& Family History & $(100.0 \%)$ & \\
\hline
\end{tabular}

Table 4. Distribution of Children According to DBP and Family History

In our study, we found prevalence of systolic hypertension in 239 (19.1\%) children out of 1250 children. Out of total 688 normal weight children $15.4 \%$ had systolic hypertension. Out of total 147 overweight children $29.9 \%$ had systolic hypertension. Out of total 94 obese children $48.9 \%$ had systolic hypertension ( $\mathrm{p}$ value 0.001 ). In our study, we found diastolic hypertension in 216 (17.3\%) children out of 1250 children. Out of total 813 normal weight children $14.5 \%$ had diastolic hypertension. Out of total 147 overweight children $28.6 \%$ had diastolic hypertension. Out of total 94 obese children $35.1 \%$ had diastolic hypertension ( $p$ value 0.001 ). A Pearson correlation was run to determine the relationship between BMI and SBP ( $\mathrm{r}=0.346)$, there was a positive correlation between BMI and SBP which was statistically significant ( $p$ value 0.001 ). There was a positive correlation between BMI and diastolic BP, which was statistically significant $(r=0.282, p=0.001)$. Distribution of mean systolic $\mathrm{BP}$ and mean diastolic BP in terms of BMI and age was observed (Table: 1,2 ).

In our study out of 239 high systolic hypertensive children, 136 children take junk food 1-2 times/week (Y1), 72 children take 2-4 times/week (Y2) and 27 children take $>4$ times/week (Y3). Statistically highly significant association was found between junk food intake and systolic hypertension ( $p$ value 0.001). In our study out of 216 high diastolic hypertensive children, 122 children take junk food 1-2 times/week (Y1), 68 children take 2-4 times/week (Y2) and 20 children takes $>4$ times/week (Y3). Statistically highly significant association was found between junk food intake and diastolic hypertension (p value 0.005). Out of total 239 systolic hypertensive children 83 were non-vegetarian and 156 were vegetarian. Statistically no significance was found ( $p$ value 0.144). Out of 216 diastolic hypertensive children 78 were non-vegetarian and 138 were vegetarian. Statistically no significance was found between DBP and dietary habit ( $\mathrm{p}$ value 0.063 ). In our study, out of 239 systolic hypertensive children $94(39.3 \%)$ had definite family history of obesity/ hypertension/DM/Stroke (Table 3). This observation is found to be not statistically significant ( $p$ value 0.499 ). In our study, out of 216 diastolic hypertensive children 80 (37.0\%) had definite family history of obesity/hypertension/DM/stroke (Table 4). This observation is found to be not statistically significant (p value 0.448). In our study, out of total 239 systolic hypertensive children, only 28 used to take extra salt with their food. This is not statistically significant ( $\mathrm{p}$ value 0.518). In our study, out of total 216 diastolic hypertensive children 196 were not taking extra salt with their food. This is not statistically significant ( $p$ value 0.494 ).

\section{DISCUSSION}

\section{Hypertension and BMI}

In this study prevalence of systolic hypertension in normal weight, overweight and obese were $15.4 \%, 29.9 \%$ and $48.9 \%$ respectively. Statistically highly significant association was found between BMI and systolic BP ( $p$ value 0.001 ). Study by Manu Raj et al showed prevalence of systolic hypertension in normal weight, overweight and obese groups were 5.38\%, $12.31 \%$ and $14.66 \%$ respectively. ${ }^{[9]}$ In this study prevalence of diastolic hypertension in normal weight, overweight and obese were $14.5 \%, 28.6 \%$ and $35.1 \%$ respectively. Statistically highly significant association was found between BMI and diastolic BP ( $p$ value 0.001 ). There was a positive correlation between BMI and systolic hypertension $(r=0.346, p$ value $0.001)$ same with diastolic hypertension $(r=0.282, p=.001)$ 
which was statistically significant. Our finding shows definite linear relationship between BMI and systolic and/or diastolic hypertension. Study by Manu Raj et al showed the prevalence of diastolic hypertension in normal weight, overweight and obese were $6.45 \%, 8.86 \%$ and $8.9 \%$ respectively. [10] These results support our study. But we found higher prevalence of hypertension in overweight and obese group in our study. The reasons may be as this study was conducted earlier in years (2003-06), both private and government schools were included in that study as well as differences in life style of children living in Kerala. A study by Ingale S, Dagar J showed the relationship between low BMI and malnourished children and hypertension and other metabolic disorders. [10]

\section{Sex and Hypertension}

In this study, out of total 239 systolic hypertensive children, $140(58.58 \%)$ were male and 99 (41.42\%) were female. It was not statistically significant (p value 0.345 ). Out of total 216 DBP hypertensive children, 126 (58.14\%) were male and 90 $(41.86 \%)$ were female. It was not statistically significant (p value 0.416 ). Jonathan M Sorof et al, showed male as compared with female had higher prevalence of hypertension $(23 \%$ vs. $16 \%, \mathrm{p}<0.1$ ) which is comparable to our study but their difference of prevalence was much higher probably because of differences in life style of children living in USA and our country. [11]

\section{Dietary Habits and Hypertension}

In our study out of total 239 systolic hypertensive children, 4 (1.67\%) not take junk/fast food, 136 (56.9\%) children take junk food 1-2 times/week (Y1),72 (30.1\%) children take 2-4 times/week (Y2) and 27 (8.3\%) children take $>4$ times/week (Y3). (Table No-24). In our study out of 216 high diastolic hypertensive children, 6 (2-8\%) not take junk/fast food, 122 (56.5\%) children take junk food 1-2 times/week (Y1), 68(31.5\%) children take 2-4 times/week (Y2) and 20 (9.2\%)children take $>4$ times/week (Y3). Though there are limited studies in literature, we found statistically highly significant association between Junk food intake and hypertension (SBP p value 0.001, DBP p value 0.005). Out of 239 systolic hypertensive children 83 (34.7\%) were nonvegetarian and $156(65.3 \%)$ were vegetarian. Again, out of 216 diastolic hypertensive children 78 (36.1\%) were nonvegetarian and 138 (63.9\%) were vegetarian. Statistically no significance was found in our study between dietary habit and hypertension (SBP $p$ value 0.144 and DBP $p$ value 0.063 ). In Verma et al, the BP of vegetarian and Non vegetarian also did not differ $(p>0.05)$. [12] This supports our study.

\section{Family History with Hypertension}

In our study, out of 239 systolic hypertensive children 94 (39.3\%) had definite family history of obesity/hypertension /DM/ Stroke and out of 216 diastolic hypertensive children 80 (37.1\%) had definite family history. This observation is found to be not statistically significant. But Verma et al; family history was significantly associated with hypertension $(\mathrm{p}<$ 0.01).[13] NK Anand et al; prevalence of hypertension in children with family history of hypertension was about 40 times than in children with no history. [13] Study by Surekha Joshi et al; around 30\% children with family history had diastolic hypertension. ${ }^{[14]}$ A case report by Khan FH, Dagar J discussed multisystem involvement in babies born with genetic defects, some presenting with early involvement of neurological and cardiovascular systems. [15] Results of these studies does not match our study, probably reason is children may be unaware about family history of any high risk diseases or may be undiagnosed cases of hypertension and diabetes might be present in family.

\section{Salt Intake and Hypertension}

In our study out of total 239 systolic hypertensive children, only $28(11.7 \%)$ used to take extra salt with their food and out of total 216 diastolic hypertensive children 20 (9.2\%)were take extra salt with their food. This is not statistically significant (SBP p value 0.518 , DBP p value 0.494 ). In present study prevalence of overweight and obesity was seen in $11.8 \%$ and $7.5 \%$ children respectively. Again, prevalence of hypertension was seen significantly high in overweight and obese children in comparison to normal weight children. Junk food consumption, dietary habits, extra salt intake, hours of TV watching, outdoor activity, mode of transport to school, family type (single/joint) etc., all has definite influence on BMI and hypertension. The results of this study can be applicable to similar future studies.

\section{CONCLUSIONS}

Prevalence of both systolic and diastolic hypertensions were significantly high in overweight and obese children in comparison to normal weight children. Strong positive association was found between body mass index (BMI) and both systolic and diastolic hypertension. Association of other risk factors such as sex, family history, dietary habits like junk food intake and extra salt intake, were also observed.

\section{REFERENCES}

[1] Anjana K, Prabhjot K, Navdeep K, et al. Variation in blood pressure among school children of Amritsar (Punjab). The Anthrpologist 2005;7(3):201-4.

[2] Chiolero A, Bovet P, Paradis G, et al. Has blood pressure increased in children in response to the obesity Epidemic? Pediatrics 2007;119(3):544-53.

[3] UNICEF, WHO, World Bank. Levels and trends in child malnutrition: UNICEF-WHO-World Bank joint child malnutrition estimates. UNICEF, New York; WHO, Geneva; World Bank, Washington DC: 2017.

[4] Steinberger J, Daniels SR, American Heart Association Atherosclerosis, Hypertension and Obesity in the Young Committee Obesity. Insulin resistance, diabetes and cardiovascular risk in children. Circulation 2003;107(10):1448-53.

[5] National High Blood Pressure Education Program working group on high blood pressure in children and Adolescents. The fourth report on the diagnosis, evaluation and treatment of high blood pressure in children and adolescents. Pediatrics $2004 ; 114$ (2 Suppl $4^{\text {th }}$ Report):555-76.

[6] Krishna P, Bajaj S, Thennarasu K, et al. Regional differences in reference blood pressure in young Indians. Indian Pediatrics 2007;44:921-3. 
[7] Luepker RV, Jacobs DR, Prineas RJ, et al. Secular trends of blood pressure and body size in a multi-ethnic adolescent population: 1986 to 1996. The Journal of Pediatrics 1999;134(6):668-74.

[8] Marwaha RK, Tandon N, Singh Y, et al. A study of growth Parameter and prevalence of overweight and obesity in school children from Delhi Indian Pediatrics 2006;43(11):943-52.

[9] Raj M, Sundaram KR, Paul M, et al. Obesity in Indian children: time trends and relationship with hypertension. The National Medical Journal of India 2007;20(6):288-93.

[10] Ingale S, Dagar J. Community based intervention for reducing undernutrition in infants and young children in Karad, Maharashtra. J Evolution Med Dent Sci 2016;5(94):6949-52.
[11] Sorof JM, Lai D, Turner J, et al. Overweight, ethnicity and the prevalence of hypertension in school-aged children. Pediatrics 2004;113(3 Pt 1):475-82.

[12] Verma M, Chhatwal J, George SM. Biophysical profile of blood pressure in school children. Indian Pediatrics 1995;32(7):749-54.

[13] Anand NK, Tandon L. Prevalence of hypertension in school going children. Indian Pediatrics 1996;33(5):37781.

[14] Joshi S, Gupta S, Tank S, et al. Essential hypertension: Antecedents in children. Indian Pediatrics 2003;40(1):249.

[15] Khan FH, Dagar J. Linear and whorled nevoid hypermelanosis with delayed milestones. J Evolution Med Dent Sci 2018;7(36):4062-3. 